\title{
SOLITARY PLASMA-CELL MYELOMA OF THE SPINE IN AN ADOLESCENT
}

\author{
CASE REPORT OF AN UNUSUAL PRESENTATION \\ NORBERT BOOS, MICHAEL GOYTAN, RICHARD FRASER, MAX AEBI
}

From McGill University, Montreal, Canada

\begin{abstract}
We report an unusual presentation of a solitary plasma-cell myeloma of the spine in an adolescent patient. Our case indicates the need to consider plasma-cell myeloma as a differential diagnosis even in younger patients.
\end{abstract}

J Bone Joint Surg [Br] 1997;79-B:812-4.

Received 10 March 1997; Accepted 15 April 1997

Monoclonal gammopathies, which include plasma-cell myeloma, are a heterogeneous group of diseases characterised by the expansion of monoclonal bone-marrow cells which produce a monoclonal immunoglobulin. ${ }^{1}$ Only $3 \%$ to $5 \%$ of patients with plasma-cell dyscrasia show a single osteolytic bone lesion due to plasma-cell infiltration without evidence of myeloma elsewhere. ${ }^{1,2}$ This tumour rarely occurs in young patients ${ }^{3}$ and the average age at presentation for a solitary plasmacytoma is 50 to 58 years. ${ }^{2} \mathrm{We}$ describe the unusual presentation of a solitary spinal plasma-cell myeloma in an adolescent patient.

\section{CASE REPORT}

A healthy, active 16-year-old girl sustained a pathological fracture of the L2 vertebra while cycling (Figs 1a and 1b). She had no previous history of a fall or back pain. A bone scan showed no uptake at other sites. Radiographs showed the characteristic appearance of a haemangioma but a bone biopsy was not performed because of the risk of massive

N. Boos, MD, Spine Fellow, Orthopaedic Surgeon

M. Goytan, MD, FRCS C, Spine Fellow, Orthopaedic Surgeon

R. Fraser, MD, FRCP, Associate Professor, Pathologist

M. Aebi, MD, FRCS C, Professor and Chairman

Division of Orthopaedic Surgery, Royal Victoria Hospital, McGill University, 687 Pine Avenue West, Montreal, Quebec, Canada H3A 1A1.

Correspondence should be sent to Dr N. Boos at the Orthopaedic University Hospital Zürich, Balgrist, Forchstrasse 340, 8008 Zürich, Switzerland

(C)1997 British Editorial Society of Bone and Joint Surgery 0301-620X/97/57750\$2.00 bleeding. The patient was treated conservatively at another hospital and resumed normal activities within three months. After a painfree interval of six years, she developed increasing mechanical back pain on strenuous activities, which was thought to be due to instability at the level of L2 to L3. When she was referred to our centre, she also complained of a burning sensation in the right L2 dermatome on bending sideways. Standard radiographs showed that the deformity had not substantially increased in six years (Fig. 1c). CT and MRI (Figs 1d to 1f) again strongly suggested a haemangioma.

Selective angiography showed a highly vascularised lesion with a large feeder vessel which was embolised. Subsequently, a complete vertebrectomy was performed by a combined posteroanterior approach with reconstruction by pedicle screw fixation (L1 to L3), posterolateral fusion and an anterior autologous fibular graft. Microscopy showed fragments of highly cellular bone marrow composed entirely of plasma cells (Fig. 1g). Immunohistochemical examination demonstrated a strong reaction for the kappa light chain in all tumour cells but investigation for the lambda chains was normal, suggesting malignant plasma-cell proliferation. Bone-marrow aspiration, electrophoresis and immunoelectrophoresis of the urine and serum were normal. A skeletal survey showed no abnormality. There was no hypercalcaemia, preoperative anaemia or renal involvement. The patient received adjuvant radiotherapy (36 Gy). Eighteen months later, she is painfree without local recurrence or any evidence of myelomatosis.

\section{DISCUSSION}

The unique feature of our case is the presentation of a solitary plasmacytoma in an adolescent with a pathological fracture which remained stationary and asymptomatic for six years. This diagnosis was not considered because of the young age of the patient and the striated multicystic radiological appearance suggesting a haemangioma.

Thorough histological examination did not provide evidence of a residue of any other lesion which could have undergone transformation into a plasmacytoma. Similarly, a reactive disease could be excluded because of the 


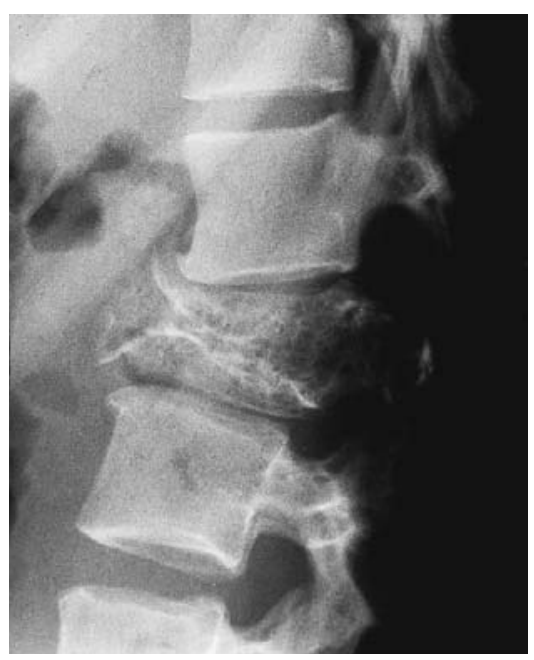

Fig. 1a

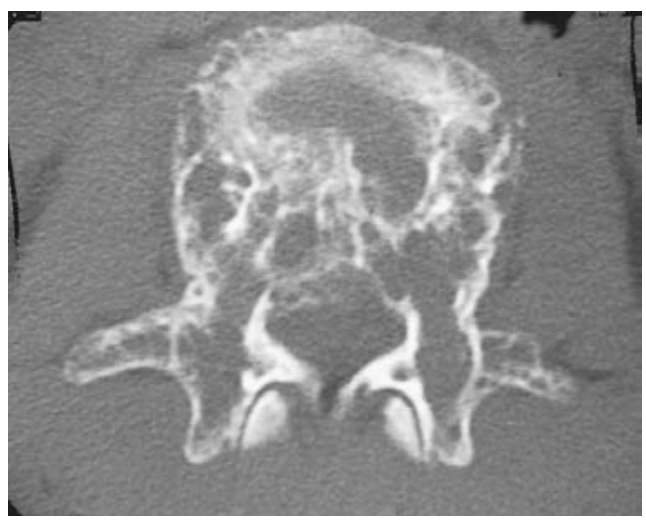

Fig. 1d

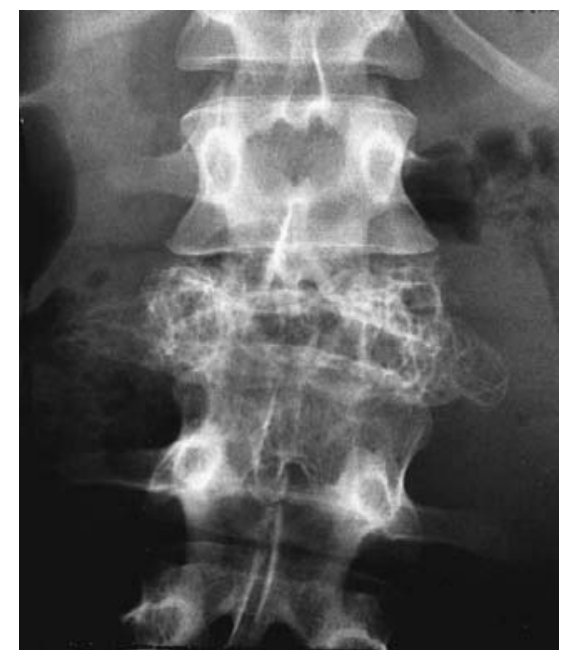

Fig. 1b

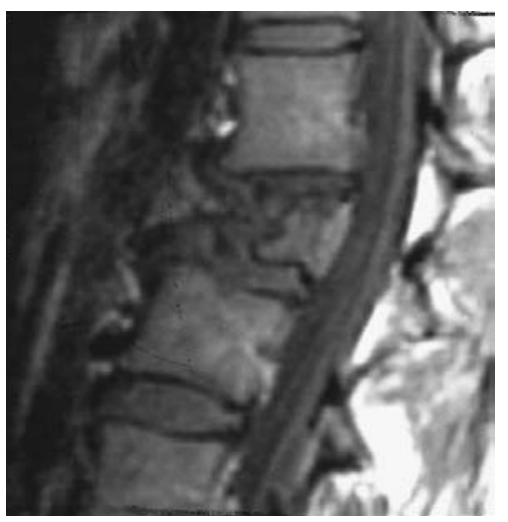

Fig. 1e

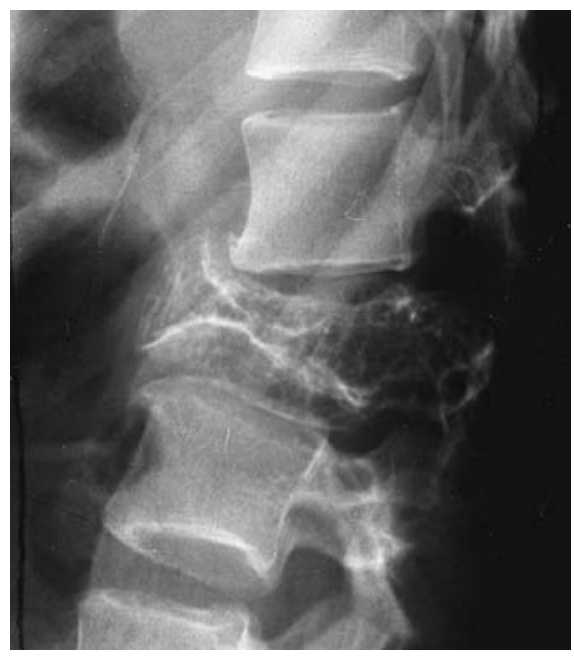

Fig. 1c

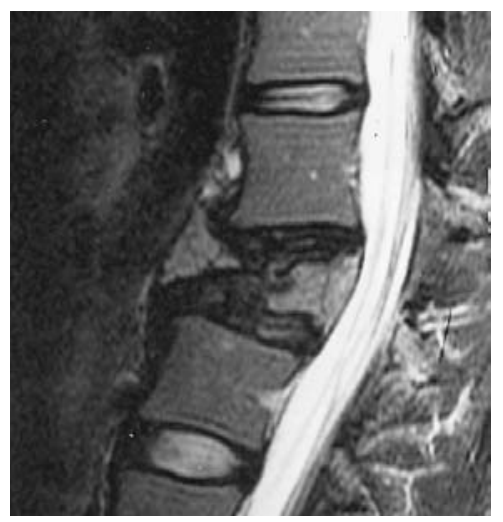

Fig. 1f

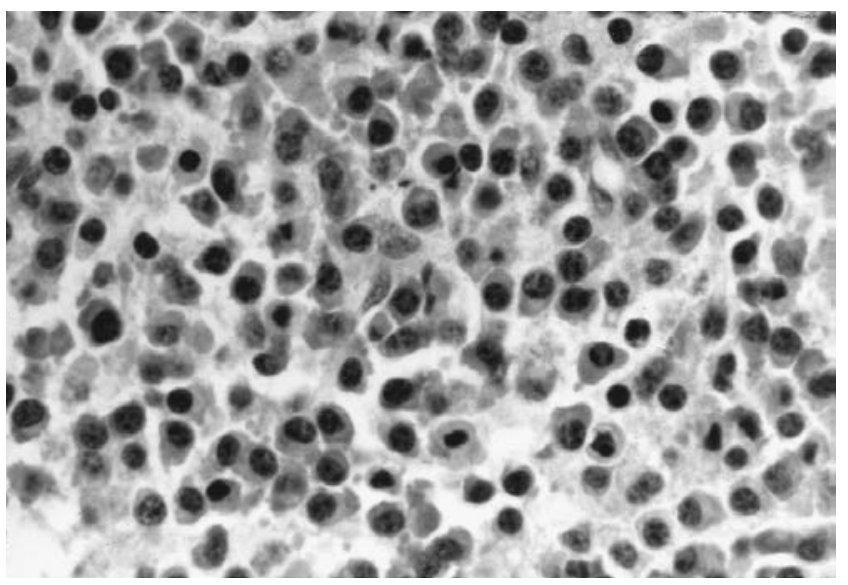

Fig. 1g

Figures 1a and $1 \mathrm{~b}$ - Anteroposterior and lateral radiographs three months after the fracture show a moderate kyphotic and scoliotic deformity. There is a multilobular osteolytic lesion. Figure $1 \mathrm{c}-\mathrm{A}$ lateral radiograph six years later shows no deterioration. Figure 1d - A preoperative CT of L2 shows osteolytic lesions in a deformed L2 vertebra. Figures 1e and 1f T1- and T2-weighted MRI shows soft-tissue infiltration of L2 and slight encroachment of the thecal sac. Figure $1 \mathrm{~g}$ - Vertebral bone marrow with a monomorphic population of mildly atypical plasma cells $(\times 110)$. 
unequivocal immunohistochemical demonstration of kappa light chains, indicating monoclonal plasma-cell proliferation, and the lack of amyloid deposition. We assume that the solitary plasmacytoma was already present at the time of the pathological fracture. A recent review of the literature by Ishida and Dorfman ${ }^{3}$ showed that 25 cases of solitary myeloma had been reported in patients at or under 30 years of age. The youngest patient with a spinal plasmacytoma reported so far is a 24-year-old man with involvement of $\mathrm{S} 1^{4}$. Our case indicates the need to consider plasma-cell myeloma as a differential diagnosis even in adolescents.
No benefits in any form have been received or will be received from a commercial party related directly or indirectly to the subject of this article.

\section{REFERENCES}

1. Boccadoro M, Pileri A. Plasma cell dyscrasias: classification, clinical and laboratory characteristics, and differential diagnosis. Baillière's Clin Haematol 1995;8:705-19.

2. Dimopoulos MA, Moulopoulos A, Delasalle K, Alexanian R. Solitary plasmacytoma of bone and asymptomatic multiple myeloma. Hematol Oncol Clin North Am 1992;6:359-69.

3. Ishida T, Dorfman HD. Plasma cell myeloma in unusually young patients: a report of two cases and review of the literature. Skeletal Radiol 1995;24:47-51.

4. McLain RF, Weinstein JN. Solitary plasmacytomas of the spine: a review of 84 cases. J Spinal Disord 1989;2:69-74 